\title{
Diabetiker können bedenkenlos Eier essen
}

\section{Hühnereier stehen noch immer im Ruf, Cholesterin- und Blutzuckertreiber zu sein. Eine Studie räumt mit diesem Vorurteil auf: Diabetiker können hart- gekochte Eier auch in großen Mengen ohne Bedenken verzehren.}

— Die Studie widmet sich der Frage, ob eine Ernährung reich an Hühnereiern

Auswirkungen auf das HDL-Cholesterin bei übergewichtigen oder adipösen Personen mit Prädiabetes oder Diabetes mellitus vom Typ 2 hat. Bisher veröffentlichte Studien zum Thema hatten widersprüchliche Ergebnisse.

Dies führte schlussendlich dazu, dass generell Empfehlungen zur Einschränkung des Eierkonsums ausgesprochen wurden.

Allerdings könnten Personen, die dieser Risikopopulation angehören, auch vom Verzehr von Eiern profitieren, da sie sehr nahrhaft sind sowie Protein und Mikronährstoffe enthalten, die zum Sättigungsgefühl und zu gutem Gewichtsmanagement beitragen.

Forscher der Universität Sydney randomisierten insgesamt 140 Patienten für drei Monate in zwei Gruppen. In einer verzehrte man an sechs Tagen pro Woche jeweils zwei Eier, in der anderen weniger als zwei Eier pro Woche.

Es zeigte sich, dass ein hoher Eierkonsum im beschriebenen Sinne keine negativen Auswirkungen auf das Lipidprofil von Personen mit Diabetes mellitus Typ 2 hat. Es gab zwischen beiden Gruppe keinen signifikanten Unterschied bis zur Kontrolle nach drei Monaten (mittlerer Unterschied: $+0,02 \mathrm{mmol} / \mathrm{l}$, 95\%-Konfidenzintervall: $-0,03$ bis 0,08 $\mathrm{mmol} / \mathrm{l}, \mathrm{p}=0,38)$.

Darüber hinaus gab es auch keine Unterschiede zwischen den beiden Gruppen bezüglich des Gesamtcholeste- rins, der Triglyzeride oder der Blutzuckerwerte. Beide Gruppen wurden hinsichtlich Protein-Nahrungsaufnahme gematcht, jedoch berichteten Patienten aus der Gruppe, in der viele Eier gegessen wurden, über weniger Hungergefühl und eine erhöhte Sättigung nach dem Frühstück.

\section{- Fuller NR, Caterson ID, Sainsbury A et al. The effect of a high-egg diet on cardiovascular risk factors in people with type 2 diabetes: the Diabetes and Egg (DIABEGG) study - a 3-mo randomized controlled trial. Am J Clin Nutr. 2015;101(4):705-13}

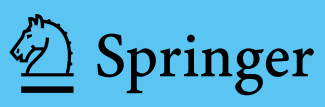

\section{Kommentar}

Aufgrund der Ergebnisse dieser Studie können Diabetiker beim Frühstück regelmäßig Eier zu sich nehmen, ohne ein schlechtes Gewissen zu haben, dass sich ihr Cholesterinwert verschlechtert und somit ihr kardiovaskuläres Risiko steigt. Ob sich die Ergebnisse der randomisierten Studie auch auf Rühreier und Spiegeleier übertragen lässt, die bekanntermaßen mit mehr Fett zubereitet werden, müssen weiterführende Studien untersuchen. Dies wäre nicht uninteressant angesichts der Beliebtheit dieser Zubereitungsformen.

Prof. Dr. med. N. Diehm .

\section{Hier steht eine Anzeige.}

